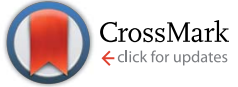

Cite this: J. Mater. Chem. A, 2016, 4, 9229

Received 17th February 2016

DOI: 10.1039/c6ta01446a

www.rsc.org/MaterialsA Accepted 24th April 2016

\section{Alkali metals as efficient A-site acceptor dopants in proton conducting $\mathrm{BaZrO}_{3}$}

\begin{abstract}
Andreas Løken, Sarmad W. Saeed, Marit N. Getz, Xin Liu and Tor S. Bjørheim*
In the present contribution, we assess the efficiency of the alkali metals ( $\mathrm{Na}, \mathrm{K}, \mathrm{Rb}$ and $\mathrm{Cs}$ ) as A-site acceptor dopants in proton conducting $\mathrm{BaZrO}_{3}$ by first principles calculations. The calculated acceptor-proton complexes become weaker with increasing dopant size, with binding energies ranging from $-0.33 \mathrm{eV}$ for $\mathrm{Na}$ to $-0.10 \mathrm{eV}$ for $\mathrm{Cs}$, which is in the range of, or even lower than, those found for B-site doped $\mathrm{BaZrO}_{3}$. By mapping out all relevant minimum energy pathways for the proton, we reveal that the highest migration energy barrier for most of the alkali metals is comparable or even lower than that of $Y$. Further, all A-site dopants display more exothermic hydration enthalpies compared to that of $\mathrm{Y}$-doped $\mathrm{BaZrO}_{3}$, ranging from $-131 \mathrm{~kJ} \mathrm{~mol}^{-1}$ to $-83 \mathrm{~kJ} \mathrm{~mol}^{-1}$ for $\mathrm{Na}$ and $\mathrm{Cs}$, respectively. The calculated dopant solubility increases in the order $\mathrm{Na}<\mathrm{Cs}<\mathrm{Rb}<\mathrm{K}$, with the predicted solubilities of the two latter being in the range of that of e.g. Y. Although Cs would lead to the highest proton mobility, the higher solubility of $\mathrm{K}$ and $\mathrm{Rb}$ renders them more attractive $\mathrm{A}$-site dopants for $\mathrm{BaZrO}_{3}$. Overall, our results suggest that alkali metals as A-site dopants may enhance the bulk proton conductivity of $\mathrm{BaZrO}_{3}$, compared to $\mathrm{Y}$-doped $\mathrm{BaZrO}_{3}$.
\end{abstract}

\section{Introduction}

Acceptor doped $\mathrm{BaZrO}_{3}$ is currently considered the most promising electrolyte for proton conducting solid oxide fuel cells and electrolysers operating at intermediate temperatures $\left(400-700{ }^{\circ} \mathrm{C}\right) .{ }^{1}$ These acceptors are charge compensated by oxygen vacancies $\left(\mathrm{v}_{\mathrm{O}}^{* \bullet}\right)$ or protons $\left(\mathrm{OH}_{\mathrm{O}}^{*}\right)$ under dry or wet conditions, respectively, in which the relative dominance of the two defects is given by the hydration reaction;

$$
\mathrm{H}_{2} \mathrm{O}(\mathrm{g})+\mathrm{v}_{\mathrm{O}}^{\bullet \bullet}+\mathrm{O}_{\mathrm{O}}^{\times} \leftrightarrows 2 \mathrm{OH}_{\mathrm{O}}^{\bullet}
$$

The thermodynamics of this equilibrium, or the enthalpy $\left(\Delta_{\text {hydr }} H^{\circ}\right)$ and entropy $\left(\Delta_{\text {hydr }} S^{\circ}\right)$ of hydration, is strongly materials dependent, and has for $\mathrm{BaZrO}_{3}$ been shown to vary with both type and amount of acceptor dopant..,3 The dopant dependency of $\Delta_{\text {hydr }} H^{\circ}$ is closely related to the strength of the complexes between the negatively charged acceptors and protons and oxygen vacancies, which again depends on the chemical mismatch between the dopant and the host ion. ${ }^{4}$

Bulk Y-doped $\mathrm{BaZrO}_{3}$ exhibits a maximum proton conductivity of $\sim 0.01 \mathrm{~S} \mathrm{~cm}^{-1}$ at $600{ }^{\circ} \mathrm{C} .{ }^{5}$ However, the practically achievable conductivity is often significantly lower and poorly reproducible. This has been attributed to a plethora of effects including large grain boundary resistances, ${ }^{6} \mathrm{Ba}$ loss and partial

Centre for Materials Science and Nanotechnology, Department of Chemistry, University of Oslo, FERMiO, Gaustadalléen 21, 0349 Oslo, Norway. E-mail: t.s. bjorheim@kjemi.uio.no
$\mathrm{Y}$ dissolution on the A-site, ${ }^{7,8}$ and complex formation and trapping. ${ }^{9-13}$ While undoped bulk $\mathrm{BaZrO}_{3}$ exhibits an activation energy of proton mobility of merely $0.16-0.20 \mathrm{eV},{ }^{9,11,12}$ nearly all B-site acceptor dopants (e.g. Sc, Y, Gd, Nd) increase this considerably due to complex formation between the acceptors and the mobile protons, thus lowering the proton conductivity. In this contribution, we explore A-site acceptor doping by alkali metals as a possible strategy to reduce the degree of proton trapping in $\mathrm{BaZrO}_{3}$, and thereby increase the proton conductivity.

Although A-site doping of $\mathrm{BaZrO}_{3}$ has been largely overlooked in literature, it has been shown to reduce the degree of defect trapping significantly compared to B-site doping in other oxides such as $\mathrm{LaScO}_{3}, \mathrm{LaGaO}_{3}$ and $\mathrm{LaNbO}_{4} \cdot{ }^{14-17}$ Additionally, experimental work on $\mathrm{BaZrO}_{3}$ co-doped with $\mathrm{K}$ on the A-site and $\mathrm{Y}$ on the B-site demonstrated that the partial proton conductivity was enhanced relative to that of Y-doped $\mathrm{BaZrO}_{3}$. However, due to the presence of multiple dopants, it is difficult to ascertain how these compositions are actually affected by K-doping. ${ }^{18,19}$ Recently, Sherafat et al. ${ }^{20}$ measured the electrical conductivity of $15 \mathrm{~mol} \% \mathrm{~K}$-doped $\mathrm{BaZrO}_{3}$, from which they evaluated its transport and defect chemical properties. $\mathrm{K}$ was shown to yield a hydration enthalpy of $-90 \mathrm{~kJ} \mathrm{~mol}^{-1}$, which is more negative than that of Y-doped $\mathrm{BaZrO}_{3}$, while the activation energy of the proton conductivity was argued to be somewhat higher than that of Y-doped $\mathrm{BaZrO}_{3}$. However, these parameters were extracted by curvefitting a defect chemical model to the total conductivity, which is often overshadowed by the grain boundary 
contribution in the temperature interval investigated (550-700 ${ }^{\circ} \mathrm{C}$ ), and may therefore not represent the true bulk properties of $\mathrm{BaZrO}_{3}$.

In this contribution, we therefore assess the efficiency of the alkali metals ( $\mathrm{M}=\mathrm{Na}, \mathrm{K}, \mathrm{Rb}$ and $\mathrm{Cs})$ as A-site acceptor dopants in $\mathrm{BaZrO}_{3}$ from first principles calculations. We determine their tendency for proton and oxygen vacancy trapping, and evaluate the relevant minimum energy pathways for the proton around the dopants, thus addressing the dopant effect on both the proton conductivity and hydration thermodynamics. Further, the dopants' effect on the chemical expansion properties of $\mathrm{BaZrO}_{3}$, and solubilities under typical synthesis conditions, are estimated.

\section{Computational methodology}

All first principles calculations were performed using Density Functional Theory (DFT) as implemented in the VASP code..$^{21,22}$ We applied the GGA-PBE exchange correlation functional ${ }^{23}$ and the core potentials were treated by the projector augmentedwave (PAW) method. ${ }^{24}$ The electronic wave functions were expanded using a set of plane waves with a constant plane-wave cut-off energy of $500 \mathrm{eV}$. The defect calculations were carried out using a $3 \times 3 \times 3$ supercell (135 atoms) expansion of an optimised unit cell of cubic $\mathrm{BaZrO}_{3}$. Electronic integration was performed using a $2 \times 2 \times 2$ Monkhorst-Pack $k$-mesh for the supercell. Additional test calculations using $4 \times 4 \times 4$ supercells (320 atoms) yielded similar results suggesting that the supercell expansions used were large enough in correspondence with other computational work on $\mathrm{BaZrO}_{3} \cdot{ }^{25}$ Ionic and electronic relaxations were carried out using convergence criteria of $0.02 \mathrm{eV} \AA^{-1}$ and $10^{-6} \mathrm{eV}$ for self-consistency, respectively.

The defect formation energies were calculated by

$$
\Delta_{\mathrm{f}} E_{\text {defect }}=E_{\text {defect }}^{\text {tot }}-E_{\text {perfect }}^{\text {tot }}-\sum_{i} \Delta n_{i} \mu_{i}+q\left(\varepsilon_{\mathrm{f}}+\Delta \varepsilon\right)
$$

where $E_{\text {defect }}^{\text {tot }}$ is the total energy of a supercell with a defect in charge state $q$, while $E_{\text {perfect }}^{\text {tot }}$ represents the total energy of the host supercell. $\Delta n_{i}$ is the difference in the number of constituent atoms with chemical potential $\mu_{i}$ between the defect and perfect supercells. $\varepsilon_{\mathrm{f}}$ is the Fermi level while $\Delta \varepsilon$ is the shift in the core potentials of the perfect and defective supercell to correct shifts in the band edges due to the jellium background charge.

The enthalpies of hydration of $\mathrm{v}_{\mathrm{O}}^{\bullet \bullet}$ in undoped and A-site acceptor doped, i.e. $\left(\mathrm{M}_{\mathrm{Ba}} \mathrm{v}_{\mathrm{O}}\right)^{\bullet}$, were calculated according to

$$
\begin{aligned}
& \Delta_{\text {hydr }} H_{\mathrm{v}_{\mathrm{o}}^{*}}=2 E_{\mathrm{OH}_{\mathrm{O}}^{*}}^{\mathrm{tot}}-E_{\mathrm{v}_{\mathrm{o}}^{\circ}}^{\mathrm{tot}}-E_{\text {perfect }}^{\mathrm{tot}}-E_{\mathrm{H}_{2} \mathrm{O}}^{\mathrm{tot}} \\
& \Delta_{\mathrm{hydr}} H_{\left(\mathrm{M}_{\mathrm{Ba}} \mathrm{v}_{\mathrm{O}}\right)^{\bullet}}=2 E_{\left(\mathrm{M}_{\mathrm{Ba}} \mathrm{OH}\right)^{\times}}^{\mathrm{tot}}-E_{\left(\mathrm{M}_{\mathrm{Ba}} \mathrm{v}_{\mathrm{O}}\right)^{\bullet}}^{\mathrm{tot}}-E_{\left(\mathrm{M}_{\mathrm{Ba}} \mathrm{O}_{\mathrm{O}}\right)^{\prime}}^{\mathrm{tot}}-E_{\mathrm{H}_{2} \mathrm{O}}^{\mathrm{tot}}
\end{aligned}
$$

where $E_{\mathrm{OH}_{\mathrm{O}}^{*}}^{\mathrm{tot}}, E_{\mathrm{v}_{\mathrm{o}}^{*}}^{\mathrm{tot}}, E_{\left(\mathrm{M}_{\mathrm{Ba}} \mathrm{O}_{\mathrm{O}}\right)^{\prime}}^{\mathrm{tot}}, E_{\left(\mathrm{M}_{\mathrm{Ba}} \mathrm{OH}_{\mathrm{O}}\right)^{\times}}^{\mathrm{tot}}$ and $E_{\left(\mathrm{M}_{\mathrm{Ba}} \mathrm{v}_{\mathrm{O}}\right)^{\bullet}}^{\mathrm{tot}}$ are the total energies of the defect supercell for the proton, oxygen vacancy, dopant, the proton-dopant and oxygen vacancydopant complexes, respectively. $E_{\text {perfect }}^{\text {tot }}$ is the total energy of the perfect supercell while $E_{\mathrm{H}_{2} \mathrm{O}}^{\text {tot }}$ is the total energy of a single water molecule as determined by DFT. Note that the total energies in eqn (3) and (4) have been adjusted with the potential alignment term in (2), although this is not explicitly included in the expressions. Proton migration pathways were evaluated for all dopants by the climbing image nudged elastic band (CI-NEB) method. ${ }^{26,27}$

Upon defect formation, the lattice may chemically expand or contract, which for a defect $i$ can be expressed through the volumetric chemical expansion coefficient;

$$
\varepsilon_{i}=\frac{1}{\delta}\left(\frac{V_{i}}{V_{0}}-1\right)
$$

where $V_{i}$ and $V_{0}$ are the volumes of the defective and perfect supercell, respectively, while $\delta$ is the number of defects per formula unit.

Free energies of dopant dissolution have been evaluated under the assumption that the dopants dissolve from $\mathrm{M}_{2} \mathrm{O}$ as binary oxides are commonly used as starting materials for the synthesis of $\mathrm{BaZrO}_{3}$. We further assume $\mathrm{ZrO}_{2}$ rich conditions as $\mathrm{BaO}$ evaporation is often encountered in the fabrication of $\mathrm{BaZrO}_{3},{ }^{3,4,7}$ and that the acceptors are fully charge-compensated by oxygen vacancies

$$
2 \mathrm{Ba}_{\mathrm{Ba}}^{\times}+\mathrm{O}_{\mathrm{O}}^{\times}+\mathrm{M}_{2} \mathrm{O}(\mathrm{s})+2 \mathrm{ZrO}_{2}(\mathrm{~s})=2 \mathrm{M}_{\mathrm{Ba}}^{\prime}+\mathrm{v}_{\mathrm{O}}^{\bullet \bullet}+2 \mathrm{BaZrO}_{3}(\mathrm{~s})
$$

with the dissolution free energy determined by

$$
\Delta_{\text {diss }} G=2 \Delta_{\mathrm{f}} G_{\mathrm{M}_{\mathrm{Ba}}^{\prime}}+\Delta_{\mathrm{f}} G_{\mathrm{v}_{\mathrm{o}}}
$$

$\Delta_{\mathrm{f}} G_{\mathrm{M}_{\mathrm{Ba}}^{\prime}}$ and $\Delta_{\mathrm{f}} G_{\mathrm{v}_{\mathrm{o}}}$ are given by the following expressions, respectively

$$
\begin{aligned}
\Delta_{\mathrm{f}} G_{\mathrm{M}_{\mathrm{Ba}}^{\prime}}= & E_{\mathrm{M}_{\mathrm{Ba}}^{\prime}}-E_{\text {perfect }}+\mu_{\mathrm{BaZrO}_{3}}-\mu_{\mathrm{ZrO}_{2}}-\frac{1}{2} \mu_{\mathrm{M}_{2} \mathrm{O}}-\frac{1}{4} \mu_{\mathrm{O}_{2}} \\
& -\left(\varepsilon_{\mathrm{f}}+\Delta \varepsilon\right) \\
& \Delta_{\mathrm{f}} G_{\mathrm{v}_{\mathrm{o}}^{\circ}}=E_{\mathrm{v}_{\mathrm{o}}^{*}}-E_{\text {perfect }}+\frac{1}{2} \mu_{\mathrm{O}_{2}}+2\left(\varepsilon_{\mathrm{f}}+\Delta \varepsilon\right)
\end{aligned}
$$

The temperature dependency of the chemical potentials, $\mu_{\mathrm{M}_{2} \mathrm{O}}, \mu_{\mathrm{ZrO}_{2}}$ and $\mu_{\mathrm{BaZrO}_{3}}$, were taken from the HSC Chemistry 8.2.0 database. $^{28}$ For $\mathrm{v}_{\mathrm{O}}^{\bullet \bullet}$, we have also included vibrational contributions to the formation energy as reported in previous work. ${ }^{2}$ For the dopants, the vibrational contributions were found to be negligible, and were therefore disregarded.

Further, the dopant solubilities have been estimated from the corresponding equilibrium constant

$$
\exp \left(-\frac{\Delta_{\mathrm{diss}} G}{R T}\right)=\left(\frac{\left[\mathrm{M}_{\mathrm{Ba}}^{\prime}\right]}{\left[\mathrm{Ba}_{\mathrm{Ba}}^{\times}\right]}\right)^{2} \frac{\left[\mathrm{v}_{\mathrm{O}}^{\bullet \bullet}\right]}{\left[\mathrm{O}_{\mathrm{O}}^{\times}\right]} \frac{a_{\mathrm{BaZrO}_{3}(\mathrm{~s})^{2}}}{a_{\mathrm{M}_{2} \mathrm{O}(\mathrm{s})} a_{\mathrm{ZrO}_{2}(\mathrm{~s})}{ }^{2}}
$$

with the following site restrictions imposed for the concentration of regular sites

$$
\begin{gathered}
{\left[\mathrm{Ba}_{\mathrm{Ba}}^{\times}\right]=1-\left[\mathrm{M}_{\mathrm{Ba}}^{\prime}\right]} \\
{\left[\mathrm{O}_{\mathrm{O}}^{\times}\right]=3-\left[\mathrm{v}_{\mathrm{O}}^{\bullet \bullet}\right]-\left[\mathrm{OH}_{\mathrm{O}}^{\bullet}\right]}
\end{gathered}
$$


where 1 and 3 (mole fractions) are the concentrations of $\mathrm{Ba}$ and O lattice sites, respectively.

\section{Results and discussion}

\section{Defect configurations and complex formation}

In the perfect $\mathrm{BaZrO}_{3}$ structure, there is only a single distinct oxygen site with four symmetrically equivalent proton configurations. ${ }^{10}$ A-site doping reduces the symmetry, resulting in two distinct proton configurations within the first coordination sphere of the dopant, one pointing towards the dopant and one away from it. In addition to these nearest-neighbour (N) positions, we have evaluated two distinct configurations within the second coordination sphere (NN) (Fig. 1).

The calculations reveal that for all A-site dopants, the proton is always most stable in configuration 1, i.e. closest to the acceptor dopant, while configurations 2-4 are less favourable (see Fig. 1). For instance for $\mathrm{Rb}$, the relative energies of configurations $1-4$ are $0,0.12,0.11$ and $0.10 \mathrm{eV}$, respectively.

Fig. 2 compares the local atomic relaxations around a proton in its most stable configuration in undoped, B-site doped and A-site doped $\mathrm{BaZrO}_{3}$. The lattice distortions are significantly larger in the B-site doped structure compared to that of the undoped system. The distortion extends far beyond the neighbouring atoms, causing a minor tilting of all surrounding octahedra. In the A-site doped system, on the other hand, the lattice distortion is minimal and barely affects the two neighbouring zirconium ions, which may indicate a local trapping effect for the A-site acceptor doped systems. Similar effects of lattice distortions on ionic conductivity have previously been observed for oxide ion transport in e.g. $\mathrm{CeO}_{2}$, where the lattice strain caused by doping increases the activation energy of oxide ion mobility by as much as $0.3 \mathrm{eV} .^{29}$

The effect of the dopant on the activation energy of proton and oxygen vacancy mobility can be estimated by evaluating the binding energies of the complexes formed between the acceptors and protons or oxygen vacancies $\left(\mathrm{M}_{\mathrm{Ba}} \mathrm{OH}_{\mathrm{O}}\right)^{\times}$and $\left(\mathrm{M}_{\mathrm{Ba}} \mathrm{V}_{\mathrm{O}}\right)^{\bullet}$. This is determined by the formation energy differences between the complexes and isolated point defects;

$$
\begin{gathered}
E_{\text {bind }}\left(\mathrm{M}_{\mathrm{Ba}} \mathrm{OH}_{\mathrm{O}}\right)^{\times}=\Delta_{\mathrm{f}} E_{\left(\mathrm{M}_{\mathrm{Ba}} \mathrm{OH}\right)^{\times}}-\Delta_{\mathrm{f}} E_{\mathrm{M}_{\mathrm{Ba}}^{\prime}}-\Delta_{\mathrm{f}} E_{\mathrm{OH}_{\mathrm{O}}^{\bullet}} \\
E_{\text {bind }}\left(\mathrm{M}_{\mathrm{Ba} \mathrm{V}_{\mathrm{O}}}\right)^{\bullet}=\Delta_{\mathrm{f}} E_{\left(\mathrm{M}_{\mathrm{Ba}} \mathrm{v}_{\mathrm{O}}\right)^{\bullet}}-\Delta_{\mathrm{f}} E_{\mathrm{M}_{\mathrm{Ba}}^{\prime}}-\Delta_{\mathrm{f}} E_{\mathrm{v}_{\mathrm{o}}^{\circ}}
\end{gathered}
$$

The calculated binding energies of $\left(\mathrm{M}_{\mathrm{Ba}} \mathrm{OH}_{\mathrm{O}}\right)^{\times}$and $\left(\mathrm{M}_{\mathrm{Ba}} \mathrm{V}_{\mathrm{O}}\right)^{\bullet}$ are presented in Fig. 3(a) and (b), respectively, as a function of the ionic radius of all the A-site dopants studied. These energies are calculated by placing the positive defects either in the nearest (1-2) or next nearest (3-4) neighbour positions to the dopant, resulting in two separate binding energies for both $\mathrm{v}_{\mathrm{O}}^{\bullet \bullet}$ and $\mathrm{OH}_{\mathrm{O}}^{\bullet}$. Only the most stable nearest $(\mathrm{N})$ and next nearest (NN) configurations to the dopant are used. The dashed vertical line represents the ionic radius of $\mathrm{Ba}^{2+}$, for reference, while the horizontal dotted line denotes zero associations between the defects, i.e. $E_{\mathrm{bind}}=0$. Additional calculations taking the relative energy differences between defects placed near and far away from the acceptors in the same supercell yielded similar values. As the figure demonstrates, almost all binding energies are exothermic, reflecting that the formation of complexes is favoured over the isolated point defects. For the proton, the binding energies for the nearest neighbour (N) configuration show an almost linear trend with respect to the ionic radii of the dopant, becoming less exothermic with increasing size ranging from -0.33 to $-0.10 \mathrm{eV}$ for $\mathrm{Na}$ to $\mathrm{Cs}$, respectively. These values are also of a similar magnitude to what has been reported for Bsite doped $\mathrm{BaZrO}_{3} .^{\mathbf{2 , 1 0 , 1 1 , 3 0}}$ For the next nearest neighbour (NN) configurations on the other hand, the binding energies are virtually independent of the dopant. Furthermore, the binding energies for the oxygen vacancy, regardless of the coordination sphere ( $\mathrm{N}$ or $\mathrm{NN}$ ), generally become more exothermic with larger differences in the ionic radii between the dopant and the host $(\mathrm{Ba})$ in correspondence with other computational work on B-site doped perovskites. ${ }^{2,4,10,11,31}$ These binding energies are otherwise very weakly exothermic with a minimum value of $-0.08 \mathrm{eV}$ for $\mathrm{Cs}$, and are thus significantly less negative than all

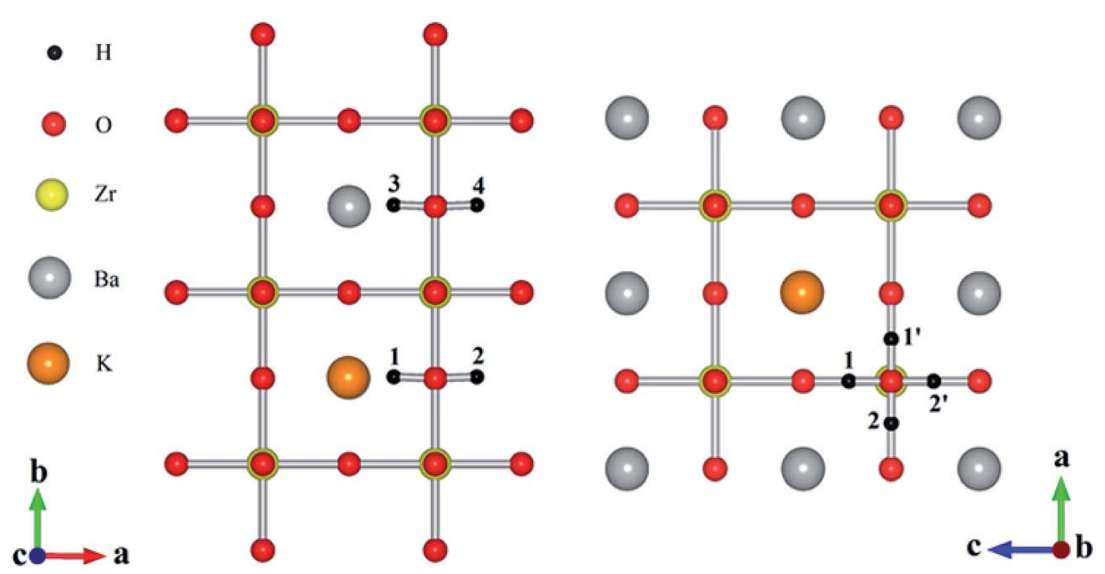

Fig. 1 The four proton configurations within the first ( 1 and 2$)$ and second (3 and 4$)$ coordination spheres considered in this work along two different projections. Note that configurations $1^{\prime}$ and $2^{\prime}$ are symmetrically equivalent to 1 and 2 , respectively. 


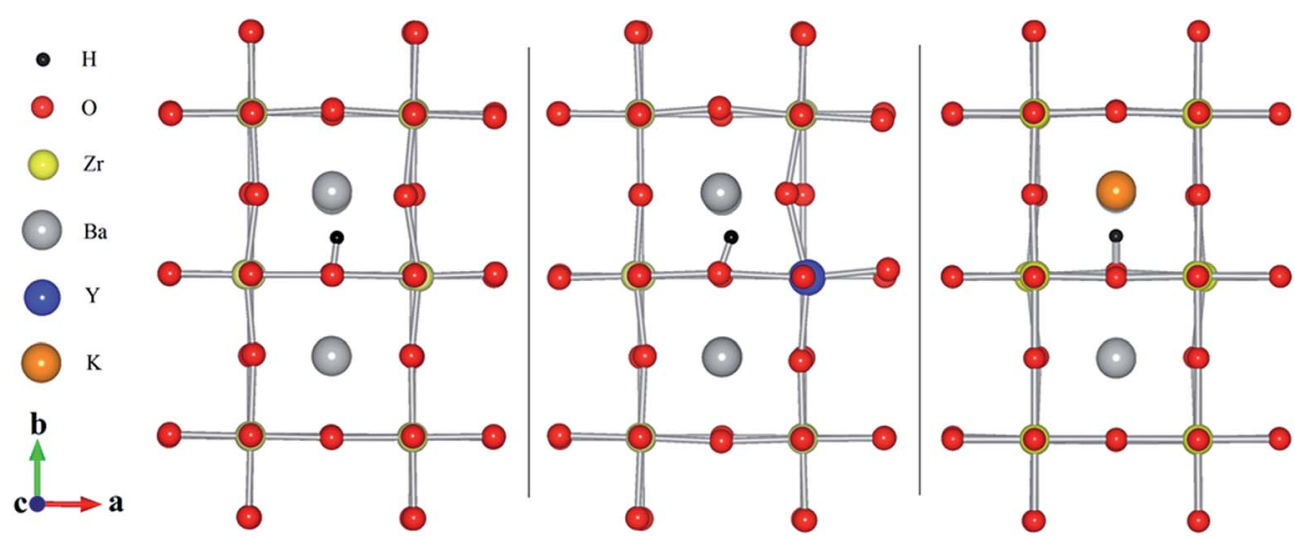

Fig. 2 Local atomic relaxations around the proton in undoped, B- and A-site doped $\mathrm{BaZrO}_{3}$ (nearest neighbour configuration). B-site doping causes the most significant lattice distortions, while $\mathrm{A}$-site doping results in less distortion than in undoped $\mathrm{BaZrO}_{3}$. Note that $\mathrm{Y}$ and $\mathrm{K}$ have here been chosen as B- and A-site dopants, respectively, and the relaxations are similar for the other dopants.
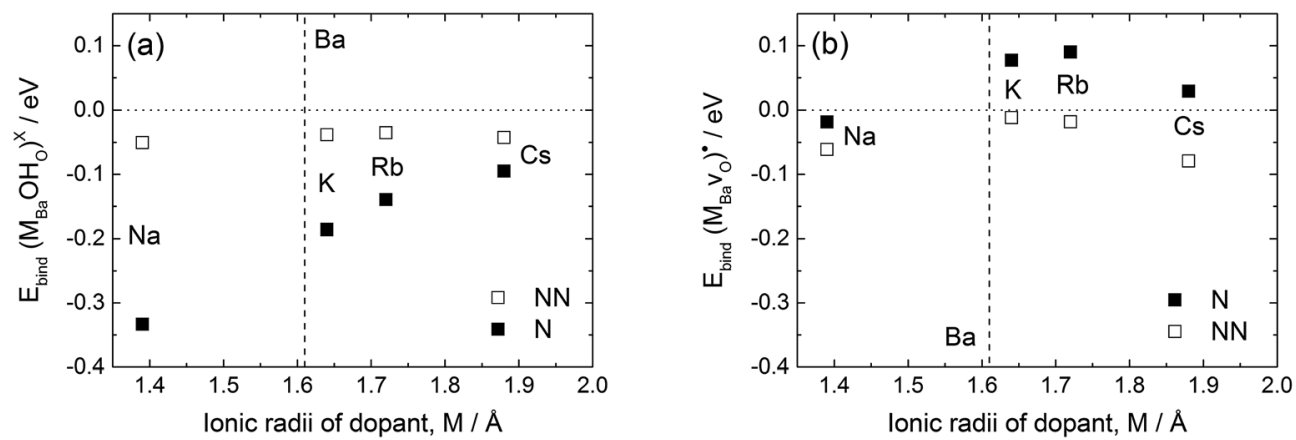

Fig. 3 (a) Calculated binding energies for the proton for $\mathrm{A}$-site doped $\mathrm{BaZrO}_{3}$ as a function of the ionic radius of the dopant, $\mathrm{M}$, and (b) the corresponding binding energies for the oxygen vacancy. These consider the most stable nearest $(\mathrm{N})$ and next nearest configurations ( $\mathrm{NN}$ ) to the dopant. The vertical line denotes the ionic radius for $\mathrm{Ba}^{2+}$ for reference, while the horizontal line represents zero associations.

work on the B-site doped counterparts, which typically display values between -0.3 and $-0.5 \mathrm{eV}^{2,10}$

\section{Proton migration}

To address the influence of the A-site dopants on proton mobility, minimum energy pathways for the rotation $(\mathrm{R})$ and transport $(\mathrm{T})$ of the proton for all dopants investigated have been mapped out. Similar proton migration pathways for Y-doped $\mathrm{BaZrO}_{3}$ have also been included for comparison. All pathways considered are shown in Fig. 4 along with the corresponding energy profiles. While R1 and R2 refer to $90^{\circ}$ rotations of the proton in the first and second coordination sphere of the dopant, respectively, T1 represents proton transport (migration) between two symmetrically equivalent sites in the nearest neighbour position. $\mathrm{T} 2$ and $\mathrm{T} 3$, on the other hand, involve proton transport further away from the dopant where in the case of $\mathrm{T} 2$, the proton moves from the first to the second coordination sphere of the dopant. As the results in Fig. 4 demonstrate, the highest proton migration energy barrier for the A-site dopants is associated with the rotation away from the dopant in the nearest neighbour configuration, and the barrier decreases with increasing size of the A-site cation, ranging from
0.24 to $0.56 \mathrm{eV}$ for $\mathrm{Cs}$ to $\mathrm{Na}$, respectively. The energy barriers for all other migration pathways are otherwise of a similar magnitude $(\sim 0.15-0.25 \mathrm{eV})$ being comparable to that of undoped $\mathrm{BaZrO}_{3}{ }^{11}$ thus indicating that A-site acceptor dopants only act as local proton traps. This is in clear contrast to that of B-site dopants where the highest energy barrier involves a rotation away from the dopant in the next nearest neighbour $(c f . \mathrm{Y}$ in Fig. 4). Also, the highest migration energy barriers for all the alkali metals, except that of $\mathrm{Na}$ (R1), are either similar to or even lower than the highest corresponding barrier for Y-doped $\mathrm{BaZrO}_{3}(\mathrm{R} 2)$, where the latter is $0.3 \mathrm{eV}$. Ultimately, this indicates that alkali metals as A-site acceptor dopants may improve the proton conductivity compared to that of Y-doped $\mathrm{BaZrO}_{3}$.

\section{Hydration thermodynamics}

Fig. 5 presents the calculated hydration enthalpies for all the A-site dopants studied as a function of the ionic radius of the dopant. The horizontal dotted line indicates the hydration enthalpy for $10 \mathrm{~mol} \% \mathrm{Y}$-doped and undoped $\mathrm{BaZrO}_{3}$ determined experimentally. ${ }^{3,32}$ The hydration enthalpies have been calculated by considering the most stable proton and oxygen vacancy positions. The enthalpies become increasingly negative 


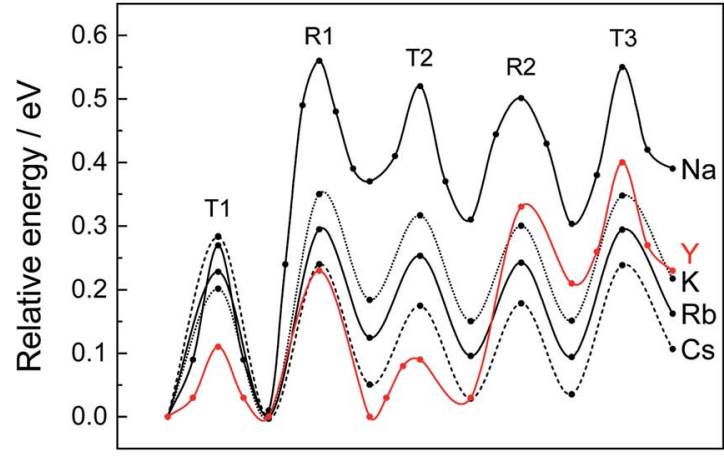

Reaction coordinate

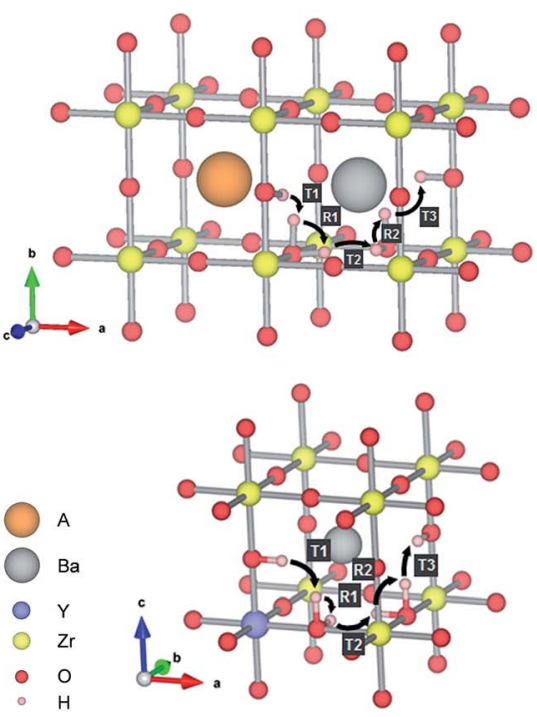

Fig. 4 NEB proton migration pathways and associated energy barriers for all A-site dopants considered (top structure) along with $\mathrm{Y}$-doped $\mathrm{BaZrO}_{3}$ (bottom structure) for comparison. The calculated points have been fitted to a modified Bézier curve to serve as a guide to the eye.

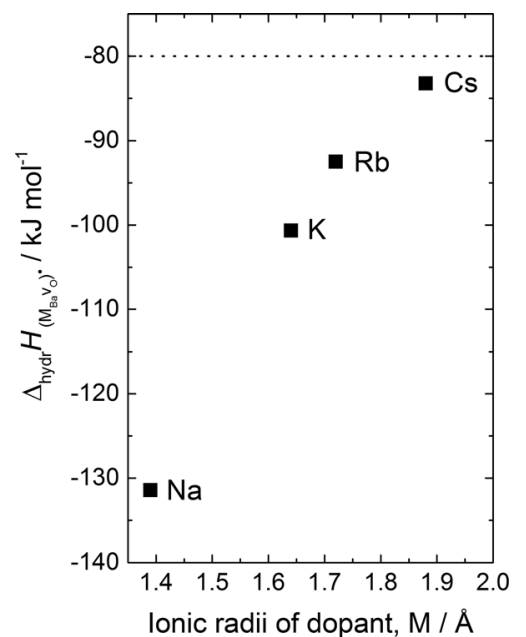

Fig. 5 Calculated hydration enthalpies of $\mathrm{A}$-site doped $\mathrm{BaZrO}_{3}$ as a function of the ionic radius of the dopant $(M=N a, K, R b$ and $C s)$. The dashed horizontal line represents experimentally determined hydration enthalpies for undoped and 10 mol\% Y-doped $\mathrm{BaZrO}_{3}{ }^{3,32}$

with decreasing ionic radius, ranging from $-83 \mathrm{~kJ} \mathrm{~mol}^{-1}$ to $-131 \mathrm{~kJ} \mathrm{~mol}^{-1}$ for $\mathrm{Cs}$ and $\mathrm{Na}$, respectively. These values are all consistently more negative than those of undoped and Y-doped $\mathrm{BaZrO}_{3}$, suggesting that A-site doping may thermodynamically stabilise the protons to higher temperatures. This is also in agreement with experimental work on $\mathrm{K}$-doped $\mathrm{BaZrO}_{3}$ by Sherafat $e t a l .^{20}$ where the hydration enthalpy was determined to be $-90 \mathrm{~kJ} \mathrm{~mol}^{-1}$. Interestingly, the more negative hydration enthalpies actually stem from an instability of the oxygen vacancies compared to in e.g. Y-doped $\mathrm{BaZrO}_{3}$, which makes them easily hydrate according to (1).

\section{Chemical expansion}

Chemical and thermal compatibility between the different components in a fuel cell or an electrolyser is essential to avoid cracking or delamination upon thermal cycling and hydration/ dehydration. Y-doped $\mathrm{BaZrO}_{3}$ exhibits a rather large chemical expansion upon hydration, ${ }^{33}$ and a further enhancement of this expansion should be avoided when choosing alternative acceptor dopants.

The chemical expansion coefficients of $\mathrm{OH}_{\mathrm{O}}^{\bullet}$ and $\mathrm{v}_{\mathrm{O}}^{\bullet \bullet}$ in the A-site acceptor doped systems have been calculated from their most stable configurations. Since the dopant concentration can be assumed frozen in at lower temperatures, the cell with a single isolated acceptor dopant is taken as the perfect reference (i.e. $V_{0}$ in (5)). From $\varepsilon_{\mathrm{OH}_{\mathrm{O}}^{*}}$ and $\varepsilon_{\mathrm{v}_{\mathrm{O}}^{*}}$, the volumetric chemical expansion upon hydration (per mole of $v_{\mathrm{O}}^{\bullet \bullet}$ ) is given by

$$
\varepsilon_{\mathrm{hydr}}=2 \varepsilon_{\mathrm{OH}_{\mathrm{O}}^{*}}-\varepsilon_{\mathrm{v}_{\mathrm{O}}}
$$

As shown in Table 1, the formation volume is negative for both defect complexes, with the oxygen vacancy formation leading to the largest contraction of the cell, similar to what is

Table 1 Formation volumes of $\mathrm{OH}_{\circ}^{\bullet}$ and $\mathrm{v}_{\mathrm{O}}^{\bullet}$, and the corresponding chemical expansion of hydration $\left(\varepsilon_{\text {hydr }}\right)$ for A-site acceptor doped $\mathrm{BaZrO}_{3}$, compared with similar values for undoped and $\mathrm{Y}$-doped $\mathrm{BaZrO}_{3}$ taken from Bjørheim et al. ${ }^{2}$

\begin{tabular}{llll}
\hline & $\left.\Delta_{\mathrm{f}} V_{\left(\mathrm{M}_{\mathrm{Ba}} \mathrm{OH}_{\mathrm{O}}\right)}\right) / \AA^{3}$ & $\Delta_{\mathrm{f}} V_{\left(\mathrm{M}_{\mathrm{Ba}} \mathrm{v}_{\mathrm{o}}\right)} \cdot / \AA^{3}$ & \\
\hline $\mathrm{Na}$ & -5.04 & -18.5 & 0.111 \\
$\mathrm{~K}$ & -4.84 & -18.2 & 0.112 \\
$\mathrm{Rb}$ & -4.48 & -18.2 & 0.121 \\
$\mathrm{Cs}$ & -3.53 & -17.6 & 0.138 \\
Undoped $^{2}$ & -4.48 & -18.1 & 0.122 \\
$\mathrm{Y}^{2}$ & -6.2 & -21.9 & 0.125
\end{tabular}



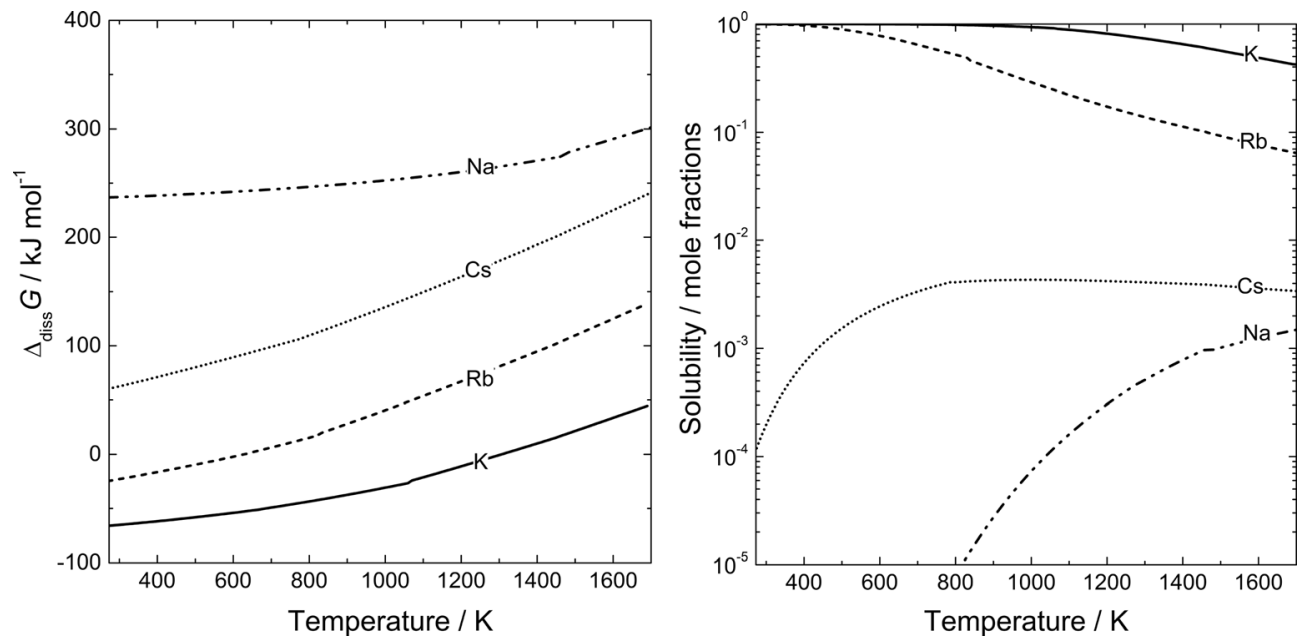

Fig. 6 Dissolution free energies and resulting equilibrium solubilities as a function of temperature according to (10) for the alkali metals in $\mathrm{BaZrO}_{3}$.

previously reported for the undoped and B-site acceptor doped system. ${ }^{2,34,35}$ These formation volumes lead to a slightly positive chemical expansion upon hydration for all four dopants, which increases with increasing dopant radii. $\mathrm{Rb}$ displays the smallest change in $\varepsilon_{\text {hydr }}$ compared to the undoped system, which can be attributed to $\mathrm{Rb}$ having a similar ionic radius to $\mathrm{Ba}$.

\section{Dopant solubility}

Our results so far suggest that the use of alkali metals as A-site acceptor dopants in $\mathrm{BaZrO}_{3}$ is a promising strategy to increase its bulk proton conductivity, with the alkali metals displaying more exothermic hydration enthalpies and similar, if not better, proton migration energies compared to $\mathrm{Y}$-doped $\mathrm{BaZrO}_{3}$. However, the implementation of these dopants requires them to be readily soluble under normal experimental conditions. Fig. 6 presents the calculated dissolution free energies and solubilities of the Asite dopants calculated according to (10)-(12).

All dissolution energies increase with increasing temperature due to the negative entropy change associated with (6). There is in addition a noticeable effect of the dopant type on the dissolution energy, which generally decreases in the order $\mathrm{Na}<\mathrm{Cs}<\mathrm{Rb}<\mathrm{K}$. While Na exhibits dissolution energies in excess of $200 \mathrm{~kJ} \mathrm{~mol}^{-1}$, that of $\mathrm{K}$ is exothermic throughout major parts of the temperature interval. This is reflected in the estimated solubilities in Fig. 6(b), with $\mathrm{K}$, and to some extent $\mathrm{Rb}$, reaching solubilities close to those of common B-site acceptor dopants such as $\mathrm{Y}$. While $\mathrm{Na}$ is predicted to barely dissolve in $\mathrm{BaZrO}_{3}$, Cs will only dissolve to a limited extent, at least when $\mathrm{BaZrO}_{3}$ is in equilibrium with $\mathrm{Cs}_{2} \mathrm{O}$. One may however speculate whether for instance ion implantation, or a low temperature synthesis route where the dopant dissolves in combination with protons, could be used to promote Cs dissolution in $\mathrm{BaZrO}_{3}$.

In summary, although Cs both shows the lowest proton binding energies and proton migration barriers (cf. Fig. 3(a) and 4), its predicted equilibrium solubility is most likely too low for practical applications. $\mathrm{K}$ and $\mathrm{Rb}$, on the hand, are highly soluble and exhibit similar proton migration barriers to that of $\mathrm{Y}$-doped $\mathrm{BaZrO}_{3}$ rendering them as interesting candidates to increase the partial proton conductivity of $\mathrm{BaZrO}_{3}$.

\section{Conclusions}

In this contribution, we have investigated the use of alkali metals as A-site acceptor dopants in $\mathrm{BaZrO}_{3}$, as alternatives to common B-site dopants such as Y. First principles calculations reveal that all selected A-site dopants give rise to more negative hydration enthalpies compared to both undoped and Y-doped $\mathrm{BaZrO}_{3}$. All dopants exhibit exothermic proton binding energies, which increase in the order $\mathrm{Cs}<\mathrm{Rb}<\mathrm{K}<\mathrm{Na}$, while the oxygen vacancy binding energies are significantly smaller. All relevant proton minimum energy pathways for the A-site dopants investigated have been mapped out and demonstrate that alkali metals only act as local proton traps where the largest barrier is associated with the rotation away from the dopant in the nearest neighbour configuration. Furthermore, the calculations reveal that the highest migration energy barrier for most of the alkali metals is comparable or even lower than that of Y. The calculated dopant dissolution energies increase in the order $\mathrm{K}<\mathrm{Rb}<\mathrm{Cs}<\mathrm{Na}$, and $\mathrm{K}$ and $\mathrm{Rb}$ are predicted to exhibit solubilities similar to those of e.g. $\mathrm{Y}$, while that of Cs and especially $\mathrm{Na}$ will be limited. Although $\mathrm{Cs}$, which displays the lowest proton migration energy barriers, would be the preferred A-site dopant in $\mathrm{BaZrO}_{3}$ to maximise the proton mobility, the higher equilibrium solubility of $\mathrm{Rb}$ renders it a more optimum overall candidate. Not only does $\mathrm{Rb}$ exhibit similar proton migration energy barriers to that of $\mathrm{Y}$-doped $\mathrm{BaZrO}_{3}$, but it also displays a hydration enthalpy that is almost $30 \%$ more negative than Y-doped $\mathrm{BaZrO}_{3}$, and would therefore stabilise protonic defects to higher temperatures. Lastly, all dopants show similar chemical expansion properties upon hydration to those of e.g. Y-doped $\mathrm{BaZrO}_{3}$ and are therefore predicted to be thermally compatible with anodes/cathodes developed for Y-doped $\mathrm{BaZrO}_{3}$. 


\section{Acknowledgements}

The authors gratefully acknowledge the Research Council of Norway (RCN), project "HydraThermPro" (project 214252) and the BIGCCS Centre (project 193816) under the Norwegian research program Centres for Environment-Friendly Energy Research (FME), and the Centre for Materials Science and Nanotechnology, for financial support. The calculations were performed on resources provided by UNINETT Sigma2 - the National Infrastructure for High Performance Computing and Data Storage in Norway.

\section{References}

1 E. Fabbri, D. Pergolesi and E. Traversa, Chem. Soc. Rev., 2010, 39, 4355-4369.

2 T. S. Bjørheim, E. A. Kotomin and J. Maier, J. Mater. Chem. A, 2015, 3, 7639-7648.

3 K. D. Kreuer, Annu. Rev. Mater. Res., 2003, 33, 333-359.

4 A. Løken, T. S. Bjørheim and R. Haugsrud, J. Mater. Chem. A, 2015, 3, 23289-23298.

5 T. Norby, in Perovskite Oxide for Solid Oxide Fuel Cells, ed. T. Ishahara, 2009.

6 C. Kjølseth, H. Fjeld, Ø. Prytz, P. I. Dahl, C. Estournès, R. Haugsrud and T. Norby, Solid State Ionics, 2010, 181, 268-275.

7 S. M. Haile, G. Staneff and K. H. Ryu, J. Mater. Sci., 2001, 36, 1149-1160.

8 A. K. Azad, C. Savaniu, S. Tao, S. Duval, P. Holtappels, R. M. Ibberson and J. T. S. Irvine, J. Mater. Chem., 2008, 18, 3414-3418.

9 Y. Yamazaki, F. Blanc, Y. Okuyama, L. Buannic, J. C. LucioVega, C. P. Grey and S. M. Haile, Nat. Mater., 2013, 12, 647-651.

10 M. E. Björketun, P. G. Sundell and G. Wahnstrom, Faraday Discuss., 2007, 134, 247-265.

11 M. E. Björketun, P. G. Sundell and G. Wahnström, Phys. Rev. B: Condens. Matter Mater. Phys., 2007, 76, 054307.

12 M. Karlsson, D. Engberg, M. E. Björketun, A. Matic, G. Wahnström, P. G. Sundell, P. Berastegui, I. Ahmed, P. Falus, B. Farago, L. Börjesson and S. Eriksson, Chem. Mater., 2010, 22, 740-742.

13 A. Cammarata, P. Ordejón, A. Emanuele and D. Duca, Chem.-Asian J., 2012, 7, 1827-1837.
14 H. Fujii, Y. Katayama, T. Shimura and H. Iwahara, J. Electroceram., 1998, 2, 119-125.

15 C. K. Vigen, T. S. Bjørheim and R. Haugsrud, Int. J. Hydrogen Energy, 2012, 37, 7983-7994.

16 M. S. Islam and R. A. Davies, J. Mater. Chem., 2004, 14, 86-93.

17 M. Huse, T. Norby and R. Haugsrud, Int. J. Hydrogen Energy, 2012, 37, 8004-8016.

18 A. S. Patnaik and A. V. Virkar, J. Electrochem. Soc., 2006, 153, A1397-A1405.

19 X. Xu, S. Tao and J. T. S. Irvine, J. Solid State Chem., 2010, 183, 93-98.

20 Z. Sherafat, M. H. Paydar, I. Antunes, N. Nasani, A. D. Brandão and D. P. Fagg, Electrochim. Acta, 2015, 165, 443-449.

21 G. Kresse and J. Furthmüller, Phys. Rev. B: Condens. Matter Mater. Phys., 1996, 54, 11169-11186.

22 G. Kresse and D. Joubert, Phys. Rev. B: Condens. Matter Mater. Phys., 1999, 59, 1758-1775.

23 J. P. Perdew, K. Burke and M. Ernzerhof, Phys. Rev. Lett., 1996, 77, 3865-3868.

24 P. E. Blöchl, Phys. Rev. B: Condens. Matter Mater. Phys., 1994, 50, 17953-17979.

25 A. Lindman, P. Erhart and G. Wahnström, Phys. Rev. B: Condens. Matter Mater. Phys., 2015, 91, 245114.

26 G. Henkelman, B. P. Uberuaga and H. Jónsson, J. Chem. Phys., 2000, 113, 9901-9904.

27 D. Sheppard, R. Terrell and G. Henkelman, J. Chem. Phys, 2008, 128, 134106.

28 HSC Chemistry 8.2.0, Outetec Technologies, 2015.

29 J. Faber, C. Geoffroy, A. Roux, A. Sylvestre and P. Abélard, Appl. Phys. A: Solids Surf., 1989, 49, 225-232.

30 S. J. Stokes and M. S. Islam, J. Mater. Chem., 2010, 20, 62586264.

31 E. Bévillon, J. Hermet, G. Dezanneau and G. Geneste, J. Mater. Chem. A, 2014, 2, 460-471.

32 C. Kjølseth, L.-Y. Wang, R. Haugsrud and T. Norby, Solid State Ionics, 2010, 181, 1740-1745.

33 A. K. E. Andersson, S. M. Selbach, C. S. Knee and T. Grande, J. Am. Ceram. Soc., 2014, 97, 2654-2661.

34 E. Jedvik, A. Lindman, M. P. Benediktsson and G. Wahnström, Solid State Ionics, 2015, 275, 2-8.

35 T. S. Bjørheim, A. Løken and R. Haugsrud, J. Mater. Chem. A, 2016, 4, 5917-5924. 